\title{
Uvular necrosis after gynecologic surgery: a case report
}

\author{
Shunaha Kim-Fine ${ }^{1 *}$, Elizabeth R. Casiano ${ }^{2}$, Christopher J. Jankowski ${ }^{1}$ and John B. Gebhart ${ }^{1}$ \\ *Correspondence: kimfine.shunaha@mayo.edu \\ 'Division of Gynecologic Surgery and Department of Anesthesiology, Mayo Clinic, Rochester, Minnesota, USA. \\ ${ }^{2}$ Department of Obstetrics and Gynecology, University of Texas Medicine Health Science Center, San Antonio, Texas, USA.
}

\begin{abstract}
Uvular necrosis is a rare complication after endotracheal intubation and upper endoscopy. A 49-year-old woman underwent surgery for uterine prolapse, rectocele, and stress urinary incontinence under general anesthesia with endotracheal intubation. The patient reported sore throat, dysphagia, and a foreign-body sensation the day after surgery. Oropharynx examination showed an inflamed uvula with a necrotic tip. She received conservative treatment and had complete symptom resolution within 2 weeks. Injury is thought to result from the uvula being compressed against the hard palate or posterior pharynx. In this instance, patient positioning may have had a role. Review of the medical literature shows that onset of sore throat, a foreign-body sensation, or odynophagia occurs within 24 hours postprocedure. Conservative management resulted in good clinical outcome in reported cases.
\end{abstract}

Keywords: Gynecologic surgical procedures, necrosis, oropharynx, trendelenburg position, uvula

\section{Background}

Sore throat commonly occurs after endotracheal intubation with an estimated incidence of $40 \%$ [1]. More serious complications related to endotracheal intubation are uncommon and include dislocation of arytenoid cartilage, aspiration of gastric contents, and damage to teeth or endotracheal mucosa. Uvular necrosis is a rare complication that has been described after endotracheal intubation and upper endoscopy. We report a case of uvular necrosis after intubation of a patient undergoing gynecologic surgery in the Trendelenburg position.

\section{Case}

A 49-year-old woman with uterine prolapse, rectocele, and stress urinary incontinence underwent vaginal hysterectomy, bilateral salpingectomy, posterior colpoperineorrhaphy, retropubic midurethral sling, placement of a suprapubic catheter, and cystoscopy. Her past medical history was significant for 2 previous upper extremity deep vein thromboses that occurred after peripheral intravenous catheter placement. She had been evaluated for an underlying thrombophilia, but none was identified. The patient also had hypertension and asthma, both of which where well controlled. She was a nonsmoker and denied sleep apnea. Her preoperative airway examination was unremarkable.

After intravenous induction of general anesthesia, direct laryngoscopy revealed a Cormack-Lehane score [2] of 1. The patient was intubated with an endotracheal tube with a 7-mm internal diameter (Hudson RCl, Temecula, California, USA) using a MAC 3 blade without difficulty. The operative procedure lasted 131 minutes, with the patient in Trendelenburg position for approximately 100 minutes. Before extubation, the pharynx and the hypopharynx were gently suctioned with a soft catheter. She was extubated without any complications. An esophageal stethoscope was used during the procedure and an oropharyngeal airway was placed after extubation for a brief duration. During the procedure, the patient had an estimated $250 \mathrm{~mL}$ of blood loss and received $700 \mathrm{~mL}$ of crystalloid intravenous fluids.

The patient reported a severe sore throat and progressive dysphagia on the day after the procedure. She also reported the sensation of having a foreign body at the back of her throat, describing it as "a strip of tissue hanging." She denied fever, chills, and other systemic symptoms of infection.

Examination of the oropharynx showed an inflamed uvula with a necrotic tip. A well-demarcated line was observed between the healthy and the necrotic tissue (Figure 1). No exudate was noted in the posterior or lateral pharynx; no cervical lymphadenopathy was detected. A treatment was started of $2 \%$ viscous lidocaine solution (swish and spit $15 \mathrm{~mL}$ every 3 hours) as needed for discomfort. An oral course of ciprofloxacin urinary tract infection prophylaxis also was prescribed on discharge from hospital, which is a standard approach for all patients with a midurethral sling at our institution. Antibiotics were not prescribed for the indication of prophylaxis against infection from uvular necrosis. The patient was discharged to home with these 2 medications on day 2 after surgery. She was reassured that the problem was self-limited, and her symptoms resolved within 2 weeks.

\section{Discussion}

Uvular necrosis is a rare complication associated with endotracheal intubation and upper endoscopy. Review of the English-language medical literature showed case reports of uvular necrosis after endotracheal intubation [3-6] and upper 
Kim-Fine et al. Journal of Anesthesiology and Clinical Science 2013,

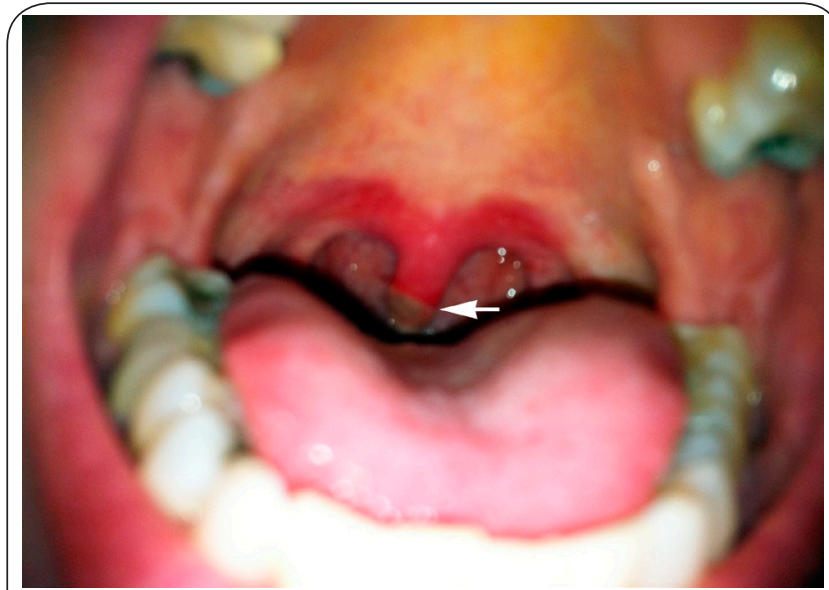

Figure 1. Inflamed Uvula With a Necrotic Tip. A white arrow shows the area of demarcation between the healthy and necrotic tissue at the tip of the uvula.

endoscopy [7]. However, we believe that this case will be the first reported in a gynecologic patient.

The pathogenesis for this injury is thought to result from compression of the uvula between the instrument (endoscope or endotracheal tube) and the hard palate or posterior pharynx. Vigorous oropharyngeal suction with a hard catheter [3] also may have an important role. Other investigators have suggested an elongated uvula as a risk factor for uvular necrosis [6].

The present patient had been placed in Trendelenburg position for the duration of her surgical procedure. Trendelenburg position increases central venous pressure and decreases venous return from the head and neck [8]. It is possible that this vascular congestion and resultant edema contributed to the occurrence of uvular necrosis in this patient. The role of patient positioning has not been reported previously as a possible etiologic factor. The rarity of this complication makes it difficult to make any specific conclusions regarding predisposing factors or preventative strategies. However, it seems reasonable that being mindful of the duration of steep Trendelenburg with occasional re-positioning out of Trendelenburg would not be harmful and may prevent this complication in gynecologic patients.

Review of the literature also showed that onset of symptoms, such as sore throat, a foreign-body sensation, or odynophagia, occurs within the first 24 hours after the procedure [3-7]. Additionally, physical examination shows a characteristic necrotic distal uvula separated from healthy tissue by a welldemarcated line [3-7]. Management of this condition has been reported to be conservative, ranging from expectant management to supportive symptomatic treatment with analgesics [5,7] and topical anesthetic [7] to use of oral antibiotics [4-7] and corticosteroids [4,7]. Overall good clinical outcome should occur in all patients. In the cases reported in the medical literature and in the present case as well, the uvula healed and the patient's symptoms resolved within 2 weeks (range, 5-14 days) [3-7] after the procedure.

\section{Conclusion}

Although report of a sore throat after endotracheal intubation is common [3], severe or persistent symptoms or the report of a foreign-body sensation in the throat should prompt further assessment and the inclusion of uvular necrosis in the differential diagnosis.

\section{Competing interests}

The authors declare that they have no competing interests.

\section{Authors' contributions}

SK-F drafted the written manuscript; ERC conceived of the case report and participated in manuscript editing; CJJ participated in manuscript editing; JBG participated in manuscript editing. All authors read and approved the final manuscript.

\section{Publication history}

Received: 24-Nov-2012 Revised: 12-Jan-2013

Accepted: 26-Jan-2013 Published: 02-Feb-2013

\section{References}

1. Biro $P$, Seifert B, Pasch T: Complaints of sore throat after tracheal intubation: a prospective evaluation. Eur J Anaesthesiol 2005, 22:307311. | Article | PubMed

2. Cormack RS, Lehane J: Difficult tracheal intubation in obstetrics. Anaesthesia 1984, 39:1105-1111. I Article I PubMed

3. Stubbing JF: Anaesthetic morbidity from trauma to the uvula. Anaesthesia 1990, 45:886-887. I Article I PubMed

4. Harris MA, Kumar M: A rare complication of endotracheal intubation. Lancet 1997, 350:1820-1821. | Article | PubMed

5. Evans DP, Lo BM: Uvular necrosis after orotracheal intubation. Am J Emerg Med 2009, 27:631 e633-634. I Article I PubMed

6. Krantz MA, Solomon DL, Poulos JG: Uvular necrosis following endotracheal intubation. J Clin Anesth 1994, 6:139-141. | Article | PubMed

7. Tang SJ, Kanwal F, Gralnek IM: Uvular necrosis after upper endoscopy: a case report and review of the literature. Endoscopy 2002, 34:585587. | Article | PubMed

8. Cassorla L, Lee J-W: Patient positioning and anesthesia. In: Miller RD, editor. Miller's Anesthesia. (7th ed). Philadelphia (PA): Churchill Livingstone/Elsevier; c2010, p.1151-70.

\section{Citation:}

Kim-Fine S, Casiano E R, Jankowski C J and Gebhart J $\mathrm{B}$ : Uvular necrosis after gynecologic surgery: a case report. journal of Anesthesiology and Clinical Science 2013, 2:9. http://dx.doi.org/10.7243/2049-9752-2-9 